\title{
A Double Heterostructure Multiplication Region in AlGaN Based SAGCM Avalanche Photodiode
}

\author{
Maryam Bagheriyeh-Behbahani, Mohammad Soroosh*, Ebrahim Farshidi \\ Department of Electrical Engineering, Shahid Chamran University of Ahvaz, Ahvaz, Iran \\ Email: *m.soroosh@scu.ac.ir
}

How to cite this paper: BagheriyehBehbahani, M., Soroosh, M. and Farshidi, E. (2017) A Double Heterostructure Multiplication Region in AlGaN Based SAGCM Avalanche Photodiode. Optics and Photonics Journal, 7, 151-159.

https://doi.org/10.4236/opj.2017.710015

Received: August 26, 2017

Accepted: October 15, 2017

Published: October 18, 2017

Copyright (c) 2017 by authors and Scientific Research Publishing Inc. This work is licensed under the Creative Commons Attribution International License (CC BY 4.0).

http://creativecommons.org/licenses/by/4.0/

\begin{abstract}
In this study, separate absorption, grading, charge, and multiplication (SAGCM) avalanche photodiode (APD) with double heterojunction $A l N / \mathrm{Al}_{\mathrm{x}} \mathrm{Ga}_{1-\mathrm{x}} \mathrm{N} / \mathrm{GaN}$ in multiplication region were designed to reduce excess noise using Monte Carlo simulation. The multiplication region was broken to three different regions and tried to enhance localization of the first and second impact ionization events at near the heterojunctions. The excess noise of the proposed structure, for high gains, was $64 \%$ smaller than that of the fabricated standard AlGaN-APDs.
\end{abstract}

\section{Keywords}

AlGaN, Avalanche Photodiode, Excess Noise, Monte Carlo Simulation

\section{Introduction}

Avalanche photodiodes (APDs) fabricated on AlGaN materials are suitable for ultraviolet (UV) wavelengths detections, enjoying advantages such as low dark current density, high receiver sensitivity, high gain, low noise, and cut-off wavelengths around $280 \mathrm{~nm}$ [1] [2] [3]. Such photodetectors, being solar-blind and capable of detecting very weak UV signals under intense background radiation, are potential substitutes for very expensive and bulky photomultiplier tubes with operating voltages in excess of 1000 volts requiring cooling systems.

Tut et al. [4] [5] have reported experimental results obtained from high performance AlGaN based APDs with high avalanche gains and cut of wavelength of $276 \mathrm{~nm}$. Their highest reported gain of 1570 was seemingly obtained from a device with multiplication region of width $\sim 200 \mathrm{~nm}$, made of $\mathrm{Al}_{0.4} \mathrm{Ga}_{0.6} \mathrm{~N}$, and reversed biased at about $70 \mathrm{~V}$ [5]. An extremely important characteristic parameter for 
such high gain APDs is their excess noise factor, which increases with the avalanche gain and it could have deteriorating effects on their performance [6]. Hence, a key challenge in designing such devices is to decrease their excess noise as far as possible. Although, in fabricating the aforementioned reproducible high performance APDs, Tut et al. have taken the necessary technological and theoretical measures for producing low noise devices, noise optimization in AlGaN based APDs by means of impact-ionization-engineered $\left(\mathrm{I}^{2} \mathrm{E}\right)$ multiplication region [7] remains to be a new challenge. Kwon et al. [8] have already employed a technique based on $\mathrm{I}^{2} \mathrm{E}$, to demonstrate optimal excess noise reduction in thin heterojunction $\mathrm{Al}_{0.6} \mathrm{Ga}_{0.4}$ As-GaAs APDs. Chen et al. [9] have simulated role of InAlGaAs grading layer on performance of InAlAs/InGaAs interfaces. Kleinov et al. have paid to the charge layer in order to optimize the InAlAs/InGaAs structure for low band discontinuities and an appropriate electric field distribution for the gains less than 300 [10]. Recently, Huang et al. [11] have studied temperature dependency of InGaAs based multiplication region APDs.

Possibility of fabricating $\mathrm{Al}_{x} \mathrm{Ga}_{1-x} \mathrm{~N}$ based hetero-interfaces with large band-gap discontinuities in one hand and having direct band-gap material for the whole $0 \leq \mathrm{x} \leq 1$ range on the other hand made us to propose a new separate absorption, grading, charge, and multiplication (SAGCM) APD, based on $\mathrm{Al}_{\mathrm{x}} \mathrm{Ga}_{1-\mathrm{x}} \mathrm{N}$ alloys. SAGM-APDs based on III-As alloys have already been employed for carrier build-up in multiplication region and reduction of dark current and excess noise factor [12] [13]. Compared with other proposals, in the proposed structure, difference between electron and hole impact ionization coefficients is compensated by broken multiplication regions. Discontinuity of bands increases impact ionization probability. This assists one to reduce fabrication challenges.

\section{The Proposed Structure}

A schematic representation of the conduction band for the proposed SAGCMAPD is illustrated in Figure 1. Thicknesses of the layers constituting the proposed device and the band discontinuities at the corresponding hetero interfaces are labeled on the figure. Role of the grading is to overcome the relatively large discontinuity between the conduction bands of $\mathrm{Al}_{0.4} \mathrm{Ga}_{0.6} \mathrm{~N}$ and $\mathrm{AlN}(\sim 1.68 \mathrm{eV})$, as well as the lattice mismatch between these two materials. Whereas, the AlN charge layer that is a highly $\mathrm{p}^{+}$doped thin AlN layer separates the absorption and multiplication layer, providing high electric field in the multiplication layer and relatively low electric field in the absorption layer.

Using ensemble Monte Carlo (EMC) simulation, we have obtained the optimized values for thicknesses of layers constituting the absorption, grading and multiplication regions; as well as the $\mathrm{Al}$ mole fraction, $x$, in various $\mathrm{Al}_{x} \mathrm{Ga}_{1-x} \mathrm{~N}$ layers, all of which, in turn, lead to an optimized value for the device excess noise factor. In optimizing the layers thicknesses in the $\mathrm{AlN} / \mathrm{Al}_{\mathrm{x}} \mathrm{Ga}_{1-\mathrm{x}} \mathrm{N} / \mathrm{GaN}$ multiplication region, we have aimed the impact ionization (II) events to be 


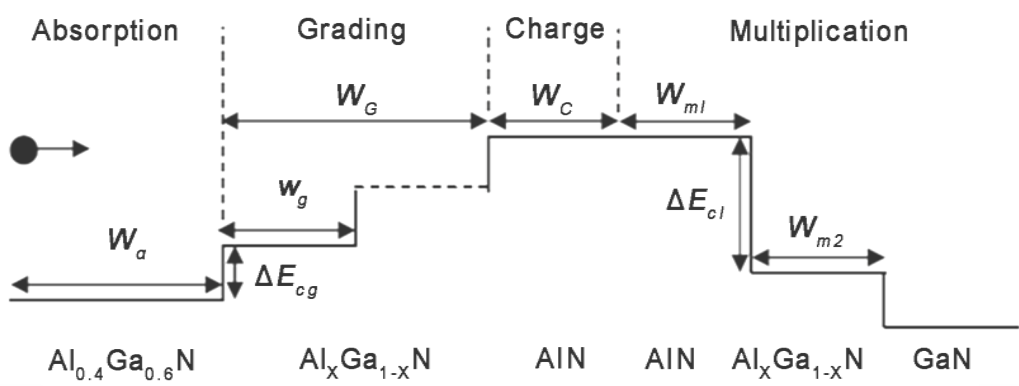

Figure 1. Schematic representation of the conduction band for the proposed SAGCM-APD (Band discontinuities are drawn not to the scale).

localized as close as possible to both $\mathrm{AlN} / \mathrm{Al}_{\mathrm{x}} \mathrm{Ga}_{1-\mathrm{x}} \mathrm{N}$ and $\mathrm{Al}_{\mathrm{x}} \mathrm{Ga}_{1-\mathrm{x}} \mathrm{N} / \mathrm{GaN}$ hetero-interfaces, in the multiplication region, but within the narrower hand-gap sides of each interface. In an optimized double heterostructure multiplication region, such as $\mathrm{AlN} / \mathrm{Al}_{\mathrm{x}} \mathrm{Ga}_{1-\mathrm{x}} \mathrm{N} / \mathrm{GaN}$, AlN should be thick enough for electrons, just before crossing over the heterointerface, to have the chance of attaining mean energies, $E_{\mathrm{M}-\mathrm{AlN}}$, very close but smaller than their corresponding ionization threshold energy, $E_{\mathrm{TH}-\mathrm{AlN}}$, and yet larger than the carriers' ionization threshold energy in the narrower band-gap material; i.e., $E_{\mathrm{TH} \text {-AIN }}>E_{\mathrm{M} \text {-AIN }}>E_{\mathrm{TH}}\left(\mathrm{Al}_{\mathrm{x}} \mathrm{Ga}_{1-\mathrm{x}} \mathrm{N}\right)$. Hence, such electrons, upon entering $\mathrm{Al}_{\mathrm{x}} \mathrm{Ga}_{1-\mathrm{x}} \mathrm{N}$, have enough energy to get involved in an II event without a need to traverse the dead space in that region. In this manner the first ionization event is localized to the hetero interface within $\mathrm{Al}_{\mathrm{x}} \mathrm{Ga}_{1-\mathrm{x}} \mathrm{N}$. In the same manner, $\mathrm{Al}_{\mathrm{x}} \mathrm{Ga}_{1-\mathrm{x}} \mathrm{N}$ also should be thick enough to localize the next ionization event adjacent to the next heterointerface and yet within the $\mathrm{GaN}$. Eliminating the carriers' dead spaces in both $\mathrm{Al}_{\mathrm{x}} \mathrm{Ga}_{1-\mathrm{x}} \mathrm{N}$ and $\mathrm{GaN}$ regions, in this manner, reduces the device excess noise factor, in effect.

As we have already mentioned, there is a relatively large band-gap discontinuity between the $\mathrm{Al}_{0.4} \mathrm{Ga}_{0.6} \mathrm{~N}\left(E_{G}=4.52 \mathrm{eV}\right)$ used for the absorption region and AlN $\left(E_{G}=6.2 \mathrm{eV}\right)$ as the starting material for the proposed APD structure. For electrons to overcome such a large barrier height, one needs to use an optimum grading region through which electrons pass with minimal transit time minimal total reflection. In one hand, for electrons to cross over a grading region with minimal reflections number of steps/layer making up the region should be maximized. On the other hand, to keep electrons transit time as short as possible, total thickness of such region should be minimized. Therefore, there are two critical design parameters by which an optimum grading region can be designed. Those are, thickness of each layer, $w_{g}$ and the barrier (step) height between to adjacent layers, $\Delta E_{c g}$ through which optimum number layers with optimum thicknesses can be obtained.

As the number of steps increases, the total reflection is reduced. Besides, if the length of grading region increases causes one can use more steps in grading region to reduce total reflection. However, as the length of grading region is increased, electron transit time cross the grading region is increased and distribu- 
tion of energy is more broaden due to more scattering. So, we reduce length of the grading region until electrons can pass through the barriers and enter in multiplication region.

Our Monte Carlo model uses an analytical approximation for the band structure involving spherical, non-parabolic for two conduction bands and two sub-bands in valence bands. Impurity, Acoustic, non-polar, polar optical phonon, and alloy scattering processes are included for carriers. II rate is described by the Keldysh approach using ionization threshold energy and softness coefficients as fitting parameters to the experimental ionization coefficient data [14]. Multiplication region is divided to 4500 cells and 20,000 super particles are used for simulation. To initiate, an electron is injected to multiplication region. It can drift and scatter in across of the multiplication region. Total careers that reach to both sides of multiplication region are counted. Number of these careers is defined as gain. This process is simulated 20,000 times. Excess noise factor is defined by ratio of the average of the square of gains to the square of the gain average [14].

\section{Results and Discussion}

To validate our MC model, we calculate electron impact ionization coefficients $(\alpha)$ and compare to calculated electron impact ionization coefficients by Bulutay for $\mathrm{Al}_{\mathrm{x}} \mathrm{Ga}_{1-\mathrm{x}} \mathrm{N}(x=0,0.2,0.4, \cdots, 1)$ as shown in Figure 2 [14].

As the $\mathrm{Al}$ mole fraction is increasing in $\mathrm{Al}_{\mathrm{x}} \mathrm{Ga}_{1-\mathrm{x}} \mathrm{N}$, electron impact ionization coefficient is reduced. More $\mathrm{Al}$ mole fraction results in the heavier carriers and wider band-gap material. So, the threshold energy for impact ionization and dead space are increased. The obtained threshold energy for electron II has given in Table 1.

According to mentioned modeling, we design and simulate the $\mathrm{DH}$ AlN/Al ${ }_{0.4} \mathrm{Ga}_{0.6} \mathrm{~N} / \mathrm{GaN}$ multiplication region SAGCM-APD (see Figure 1). Photons are absorbed in $\mathrm{Al}_{0.4} \mathrm{Ga}_{0.6} \mathrm{~N}$ region where distances of photon absorption from illuminated edge are distributed exponentially. We select $W_{a}=200 \mathrm{~nm}$ results in more than $90 \%$ of entering photons is absorbed in $\mathrm{Al}_{0.4} \mathrm{Ga}_{0.6} \mathrm{~N}$. Details of different layers are given for proposed SAGCM-APD in Table 2. $W_{m 1}$ and $W_{m 2}$ are calculated for different charge layers.

As the length of the grading region shrinks, mean transit time through the barriers reduces and distribution of energy of electrons becomes almost narrow. However, one can shrink grading regions until the electrons can pass the grading region. So, the number of steps $\left(N_{\text {step }}\right)$ and length of the grading region $\left(W_{G}\right)$ are key parameters. We considered the different lengths of grading layer and grading region, which our simulations demonstrated the minimum length of the grading region is $88 \mathrm{~nm}$ with $N_{\text {step }}=9$ where electrons could inject to charge region. Also, our simulations demonstrated the full width at half maximum (FWHM) in distribution of energy for electrons at end of the grading region is almost increased $\sim 0.011 \mathrm{ev}$ and $0.002 \mathrm{ev}$ for each $1 \mathrm{~nm}$ increasing in grading 


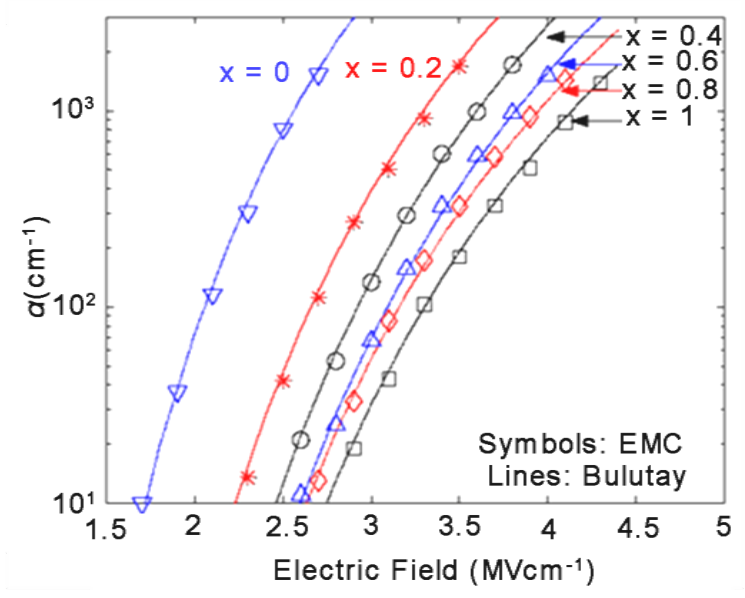

Figure 2. Electron impact ionization coefficients versus electric field, in $\mathrm{Al}_{\mathrm{x}} \mathrm{Ga}_{1-\mathrm{x}} \mathrm{N}$, for various $x$, obtained by EMC simulation (symbols) compared with calculated results (lines) obtained from Bulutay [14].

Table 1. Threshold energy for electron II events.

\begin{tabular}{cccccccc}
\hline $\mathrm{Al}$ content $(\mathrm{x})$ in $\mathrm{Al}_{\mathrm{x}} \mathrm{Ga}_{1-\mathrm{x}} \mathrm{N}$ & 0 & 0.2 & 0.4 & 0.6 & 0.8 & 1 \\
$E_{T H}(\mathrm{eV})$ & 4 & 4.5 & 5.2 & 5.7 & 6.3 & 6.8 \\
\hline
\end{tabular}

Table 2. Details of the proposed SAGCM-APD.

\begin{tabular}{|c|c|c|c|c|c|c|c|c|c|c|}
\hline \multirow{2}{*}{\multicolumn{2}{|c|}{$\mathrm{n}^{+}-\mathrm{GaN}$}} & \multicolumn{3}{|c|}{$\begin{array}{c}\text { Multiplication } \\
{\left[N_{A}=10^{16}\left(\mathrm{~cm}^{-3}\right)\right]}\end{array}$} & \multirow{2}{*}{\multicolumn{2}{|c|}{$\begin{array}{l}\text { Charge } \\
\mathrm{p}^{+} \text {-AlN }\end{array}$}} & \multirow{2}{*}{\multicolumn{2}{|c|}{$\begin{array}{c}\text { 9-steps Grading } \\
\text {-- }-\mathrm{Al}_{\mathrm{x}} \mathrm{G}_{1-\mathrm{x}} \mathrm{N}(0.4 \leq \mathrm{x} \leq 1)\end{array}$}} & \multirow{2}{*}{\multicolumn{2}{|c|}{$\begin{array}{c}\text { Absorption } \\
\mathrm{p}^{-} \mathrm{Al}_{0.4} \mathrm{Ga}_{0.6} \mathrm{~N}\end{array}$}} \\
\hline & & $\mathrm{p}^{-} \mathrm{GaN}$ & $\mathrm{p}^{-} \mathrm{Al}_{0.4} \mathrm{Ga}_{0.6} \mathrm{~N}$ & $\mathrm{p}^{-} \mathrm{AlN}$ & & & & & & \\
\hline$N_{D}^{+}$ & $W$ & $W_{m 3}$ & $W_{m 2}(\mathrm{~nm})$ & $W_{m 1}(\mathrm{~nm})$ & $N_{A}\left(10^{17} \mathrm{~cm}^{-3}\right)$ & $W_{\mathrm{C}}(\mathrm{nm})$ & $N_{A}$ & $W_{G}$ & $N_{A}$ & $W_{\mathrm{a}}$ \\
\hline \multirow{5}{*}{$2 \times 10^{18} \mathrm{~cm}^{-3}$} & & & 50 & 78 & 5 & 30 & \multirow{5}{*}{$10^{16} \mathrm{~cm}^{-3}$} & \multirow{5}{*}{$88 \mathrm{~nm}$} & \multirow{5}{*}{$10^{16} \mathrm{~cm}^{-3}$} & \multirow{5}{*}{$200 \mathrm{~nm}$} \\
\hline & & & 50 & 74 & 4.6 & 35 & & & & \\
\hline & $30 \mathrm{~nm}$ & $250 \mathrm{~nm}$ & 48 & 72 & 4 & 40 & & & & \\
\hline & & & 46 & 70 & 3.6 & 45 & & & & \\
\hline & & & 46 & 66 & 3.1 & 50 & & & & \\
\hline
\end{tabular}

layers and each one step decreasing respectively. As the FWHM is larger, the distribution of energy is more broaden.

To compare different charge layers (that are tabulated in Table 2), we calculate FWHM in distribution of energy for electrons at end of the charge region. One can see FWHM is increased $\sim 0.04 \mathrm{ev}$ for each $5 \mathrm{~nm}$ increasing in length of the charge layer (see Table 3).

Injected energized electrons from charge to multiplication region need to almost short dead space to gain the threshold energy for II in AlN. Maximum electric field in multiplication region is lower than $2.7 \mathrm{MV} \cdot \mathrm{cm}^{-1}$ to breakdown is not occurred in GaN. We select mean distance of first II events in $\mathrm{Al}_{\mathrm{x}} \mathrm{Ga}_{1-\mathrm{x}} \mathrm{N}$ 
Table 3. FWHM of electron energy distribution at end of the different charge layers.

\begin{tabular}{cccccc}
\hline$W_{C}(\mathrm{~nm})$ & 30 & 35 & 40 & 45 & 50 \\
FWHM $(\mathrm{eV})$ & 1.06 & 1.09 & 1.12 & 1.16 & 1.21 \\
\hline
\end{tabular}

from $\mathrm{AlN} / \mathrm{Al}_{\mathrm{x}} \mathrm{Ga}_{1-\mathrm{x}} \mathrm{N}$ hetero-interface $\left(<\delta_{1}>\right)$ as a criterion to study the localization of first II events in $\mathrm{Al}_{\mathrm{x}} \mathrm{Ga}_{1-\mathrm{x}} \mathrm{N}$. The minimum value for $\delta_{1}$ is obtained with $W_{m l}=78 \mathrm{~nm}$, and $\mathrm{Al}$ mole fraction, $\mathrm{x}=0.4$. Figure 3 shows $\delta_{1}$ with different $\mathrm{Al}$ mole fractions.

Existence of an optimum value for $\mathrm{Al}$ mole fraction $(x)$ is due to two issues whose effects on $\delta_{1}$ are in opposite direct; 1) reflection from hetero-interface, and 2) access to more energy due to discontinuity of energy at hetero-interface. In one hand, $\mathrm{As}$ the $\mathrm{Al}$ content in $\mathrm{Al}_{\mathrm{x}} \mathrm{Ga}_{1-\mathrm{x}} \mathrm{N}$ is reduced, reflection from hetero-interface $\mathrm{AlN} / \mathrm{Al}_{\mathrm{x}} \mathrm{Ga}_{1-\mathrm{x}} \mathrm{N}$ is increased. Some reflected electrons can gain the more energy from electric field to ionize in AlN region. After the ionization event, they have low energy when are injected (transmitted) to $\mathrm{Al}_{\mathrm{x}} \mathrm{Ga}_{1-\mathrm{x}} \mathrm{N}$ region. Also, scattering processes can reduce the energy of other reflected electrons. So, they need to long dead space to can be ionized in $\mathrm{Al}_{\mathrm{x}} \mathrm{Ga}_{1-\mathrm{x}} \mathrm{N}$ region. This issue degrades the localization of impact ionization events at near the hetero-interface.

On the other hand, As the $\mathrm{Al}$ content in $\mathrm{Al}_{\mathrm{x}} \mathrm{Ga}_{1-\mathrm{x}} \mathrm{N}$ is reduced, discontinuity of energy at hetero-interface is increased. So, the probability of II occurrence for transmitted electrons to $\mathrm{Al}_{\mathrm{x}} \mathrm{Ga}_{1-\mathrm{x}} \mathrm{N}$ is increased and transmitted electrons are ionized near the hetero-interface in $\mathrm{Al}_{\mathrm{x}} \mathrm{Ga}_{1-\mathrm{x}} \mathrm{N}$. Knowing all these, we deduce from Figure 3, access to more energy due to discontinuity of energy at hetero-interface has dominant effect on reduction of $\delta_{1}$ for $\mathrm{x} \geq 0.4$ while reflection from hetero-interface increases $\delta_{1}$ for $\mathrm{x}<0.4$.

After first II events in $\mathrm{Al}_{0.4} \mathrm{Ga}_{0.6} \mathrm{~N}$, electrons with different initial energies drift to $\mathrm{GaN}$ region and can gain the threshold energy to ionization. Figure 4 demonstrates $<\delta_{2}>$ for $\mathrm{Al}_{0.4} \mathrm{Ga}_{0.6} \mathrm{~N} / \mathrm{GaN}$ with different lengths of $\mathrm{Al}_{0.4} \mathrm{Ga}_{0.6} \mathrm{~N}$ region.

One can see the minimum $\delta_{2}$ is obtained when the length of $\mathrm{Al}_{0.4} \mathrm{Ga}_{0.6} \mathrm{~N}\left(W_{m 2}\right)$ region is $50 \mathrm{~nm}$. Our simulations demonstrates II events in $\mathrm{Al}_{0.4} \mathrm{Ga}_{0.6} \mathrm{~N}$ occur for $W_{m 2}>50 \mathrm{~nm}$. This issue degrades localization of second II events in GaN for $W_{m 2}>50 \mathrm{~nm}$, because after II in $\mathrm{Al}_{0.4} \mathrm{Ga}_{0.6} \mathrm{~N}$, electrons have low energy and need to long dead space to ionized in GaN. Now, we calculate excess noise factor $(F)$ for two different devices: a) a fabricated homojunction $\mathrm{Al}_{0.4} \mathrm{Ga}_{0.6} \mathrm{~N}$ pin-APD [4], and b) our proposed SAGCM-APD with $W_{C}=30 \mathrm{~nm}$ (see Figure 5).

Our simulation demonstrates the proposed SAGCM can reduce excess noise $\sim 64 \%$ than a fabricated device for $M \approx 900$ [4]. We have calculated the mean time for electrons from generation in absorption region to exit from $\mathrm{n}^{+} \mathrm{GaN}$ region, $\tau_{d}$ for two mentioned devices in Figure 6. In high gain regimes, electrons gain high energy from high electric field and drift rapidly. Although, SAGCM structure has more delay time than fabricated pin structure [4], our simulations show the delay time is decreased for high gains. 


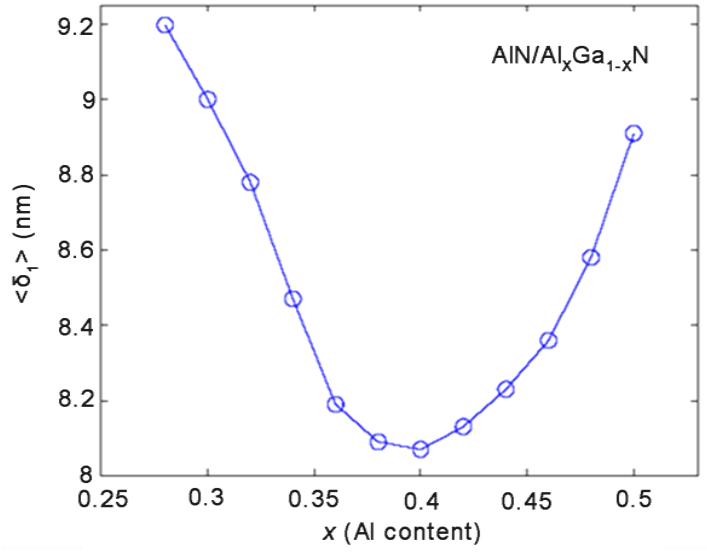

Figure 3. Average distance of first II events in $\mathrm{Al}_{\mathrm{x}} \mathrm{Ga}_{1-\mathrm{x}} \mathrm{N}$ from hetero-interface $\mathrm{AlN} / \mathrm{Al}_{\mathrm{x}} \mathrm{Ga}_{1-\mathrm{x}} \mathrm{N}$ with different $\mathrm{Al}$ mole fractions and $W_{m 1}=78 \mathrm{~nm}$.

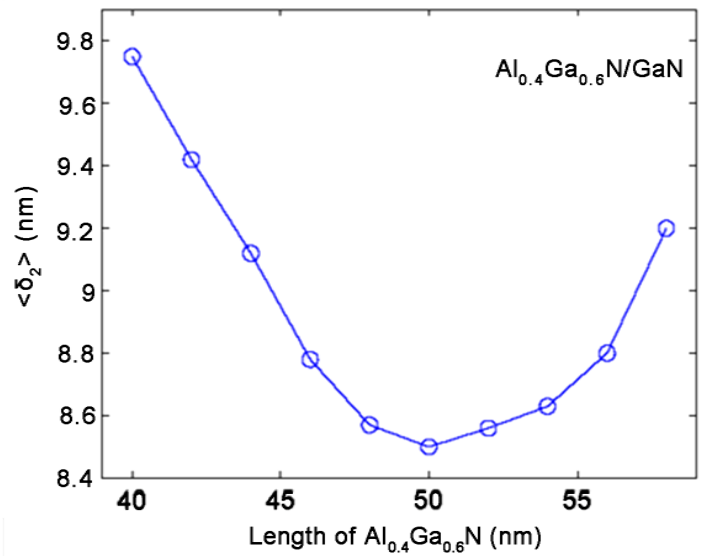

Figure 4. Average distance of second II events in GaN from $\mathrm{Al}_{0.4} \mathrm{Ga}_{0.6} \mathrm{~N} / \mathrm{GaN}$ hetero-interface with different lengths of $\mathrm{Al}_{0.4} \mathrm{Ga}_{0.6} \mathrm{~N}$ region.

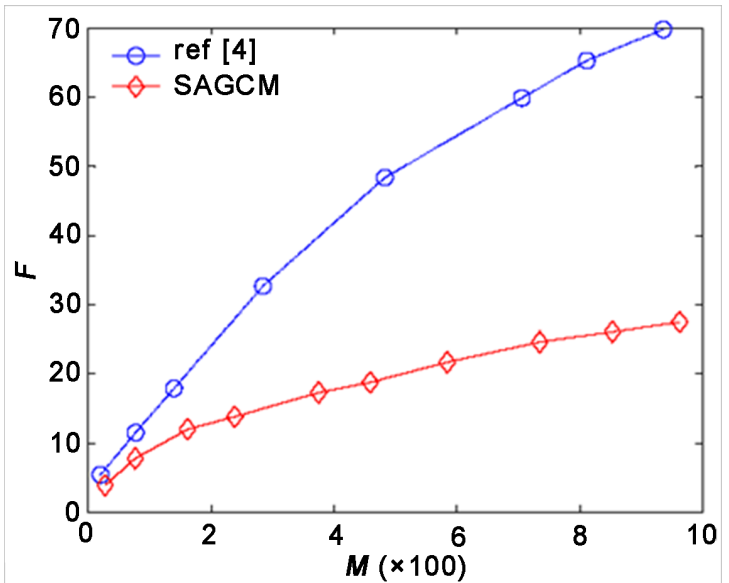

Figure 5. Calculated excess noise factor $(F)$ versus multiplication $(M)$ for the proposed SAGCM with $W_{C}=30 \mathrm{~nm}$ and a fabricated homojunction pin-APD in ref [4]. 


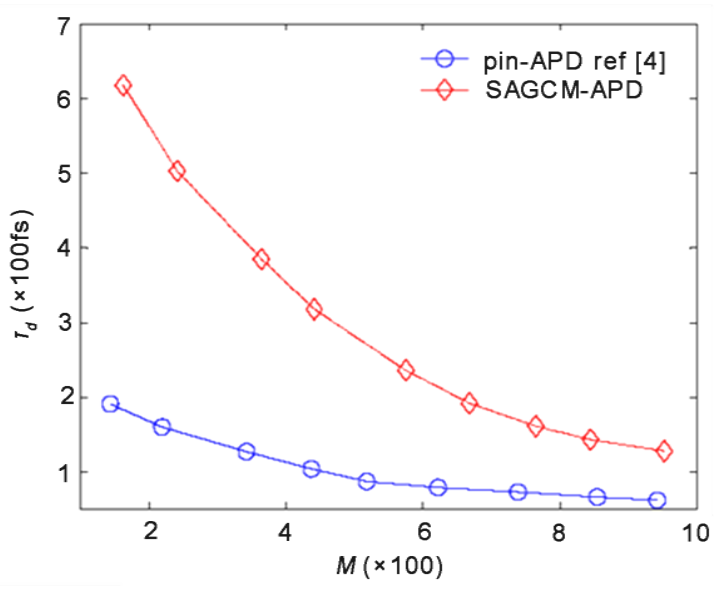

Figure 6. Calculated mean time for electrons from generation in absorption region to exit from $\mathrm{n}^{+} \mathrm{GaN}$ region with different multiplication factors.

Our simulations demonstrate the delay time for SAGCM is almost reduced exponentially with gain and it's $\sim 65$ fs longer than a fabricated pin-APD [4] for $M \approx 900$ while its excess noise is only $\sim 26.6$ at this gain. To reduce total noise in system, one employs ADPs in high gain regimes to remove amplifier block after photodetection. So, in high gain applications, the proposed SAGCM device can be used to reduce excess noise mainly.

\section{Conclusion}

In this study, we presented and designed a wide band gap SAGCM-APD with $\mathrm{Al}_{0.4} \mathrm{Ga}_{0.6} \mathrm{~N}$ in absorption region and a $\mathrm{DH}$ AlN/Al $/ \mathrm{Al}_{0.4} \mathrm{Ga}_{0.6} \mathrm{~N} / \mathrm{GaN}$ in multiplication region to reduce excess noise. Our study demonstrated that the large amount of conduction band discontinuity, always, did not enhance localization of impact ionization events near the hetero-interface. In fact, less $\mathrm{Al}$ content $(\mathrm{x})$ in $\mathrm{Al}_{\mathrm{x}} \mathrm{Ga}_{1-\mathrm{x}} \mathrm{N}$ (or more discontinuity in $\mathrm{AlN} / \mathrm{Al}_{\mathrm{x}} \mathrm{Ga}_{1-\mathrm{x}} \mathrm{N}$ ) results in more reflection which destroys the localization of first impact ionization events in $\mathrm{Al}_{\mathrm{x}} \mathrm{Ga}_{1-\mathrm{x}} \mathrm{N}$ and has dominant effect on excess noise for $\mathrm{x}<0.4$. We divided the large discontinuity between AlN and GaN in two smaller discontinuities to enhance the first and second localizations. Length of grading layer, number and size of steps in grading layer are key parameters to design. Our simulation demonstrates that one can shrink the length of grading region until $88 \mathrm{~nm}$ (with 9 steps) where the carriers can pass the grading layers. We showed that $30 \mathrm{~nm}$ for length and $5 \times 10^{17}$ $\mathrm{cm}^{-3}$ for doping concentration of charge layer are good choice. Using these issues, we could mainly reduce excess noise than a fabricated pin-APD for high gains.

\section{References}

[1] Razeghi, M. and Rogalski, A. (2012) Semiconductor Ultraviolet Detectors. Journal of Applied Physics, 79, 7433-7473. https://doi.org/10.1063/1.362677 
[2] Shen, S.C., Zhang, Y., Yoo, D., Limb, J., Ryou, J.H., Yoder, P.D. and Dupuis, R.D. (2007) Performance of Deep Ultraviolet GaN Avalanche Photodiodes Grown by MOCVD. IEEE Photonics Technology Letters, 19, 1744-1746. https://doi.org/10.1109/LPT.2007.906052

[3] Yoo, D., Limb, H., Ryou, J. H., Zhang, Y., Shen, S.C., Dupuis, R.D., Hanser, D., Preble, E. and Evans, K. (2007) $\mathrm{Al}_{\mathrm{x}} \mathrm{Ga}_{1-\mathrm{x}} \mathrm{N}$ Ultraviolet Avalanche Photodiodes Grown on GaN Substrates. IEEE Photonics Technology Letters, 19, 1313-1315. https://doi.org/10.1109/LPT.2007.902376

[4] Tut, T., Butun, B., Gokkavas, M. and Ozbay, E. (2008) $\mathrm{Al}_{\mathrm{x}} \mathrm{Ga}_{1-\mathrm{x}} \mathrm{N}$-Based Avalanche Photodiodes with High Reproducible Avalanche Gain. Physica Status Solidi (C), 5, 2316-2319. https://doi.org/10.1002/pssc.200778735

[5] Tut, T., Butun, B., Gokkavas, M. and Ozbay, E. (2007) High Performance $\mathrm{Al}_{\mathrm{x}-\mathrm{f}}$ $\mathrm{Ga}_{1-\mathrm{x}} \mathrm{N}$-Based Avalanche Photodiodes, Photonics and Nanostructures-Fundamentals and Applications, 5, 140-144. https://doi.org/10.1016/j.photonics.2007.05.001

[6] David, J.P.R. and Tan, C.H. (2008) Material Considerations for Avalanche Photodiodes. IEEE Journal of Selected Topics in Quantum Electronics, 14, 998-1009. https://doi.org/10.1109/JSTQE.2008.918313

[7] Wang, S., Sidhu, R., Zheng, X.G., Li, X., Sun, X., Holmes, A.L. and Campbell, J.C. (2001) Low-Noise Avalanche Photodiodes with Graded Impact-Ionization-Engineered Multiplication Region. IEEE Photonics Technology Letters, 13, 1346-1348. https://doi.org/10.1109/68.969903

[8] Kwon, O.H., Hayat, M.M., Wang, S., Campbell, J.C., Holmes, A., Pan, Y., Saleh, B. E.A. and Teich, M.C. (2003) Optimal Excess Noise Reduction in Thin Heterojunction $\mathrm{Al}_{0.6} \mathrm{Ga}_{0.4} \mathrm{As}-\mathrm{GaAs}$ Avalanche Photodiodes. IEEE Journal of Quantum Electronics, 39, 1287-1296. https://doi.org/10.1109/JQE.2003.817671

[9] Chen, J., Zhang, Z., Zhu, M. and Li. X. (2017) Optimization of InGaAs/InAlAs Avalanche Photodiodes. Nanoscale Research Letters, 12, 33-38.

[10] Kleiniw, P., Rutz, F., Aidam, R., Bronner, W., Heussen, H. and Wlther, M. (2015) Charge-Layer Design Considerations in SAGCM InGaAs/InAlAs Avalanche Photodiodes. Physica Status Solidi $(A), 213,925-929$. https://doi.org/10.1002/pssa.201532556

[11] Huang, J.J.-S., Chang, H.S., Jan, Y.-H., Ni, C.J., Chen, H.S. and Chou, E. (2017) Temperature Dependence Study of Mesa-Type InGaAs/InAlAs Avalanche Photodiode Characteristics. Advances in OptoElectronics, 46, 132-136.

[12] Wu, Z., Tu, J., Tian, Y., Guo, J. and Zhao, Y. (2017) Time Domain Analysis of Hole Trapping Effect in Avalanche Photodiode Using Schrödinger's Equation. IEEE Electron Device Letters, 38, 493-496.

[13] Farrel, A.C., Senanayake, P., Hung, C.H., Hovayake, G.E., Rajagopal, A., Currie, M., Hayat, M.M. and Huffaker, D.L. (2015) Plasmonic Field Confinement for Separate Absorption-Multiplication in InGaAs Nanopillar Avalanche Photodiodes. Scientific Reports, 5, 37-39. https://doi.org/10.1038/srep17580

[14] Bulutay, C. (2002) Electron Initiated Impact Ionization in AlGaN Alloys. Semiconductor Science and Technology, 17, 59-62. 